\title{
Congenital myopathy with internal nuclei and atypical cores
}

INSERM

\section{Source}

INSERM. (1999). Orphanet: an online rare disease and orphan drug data base. Congenital myopathy with internal nuclei and atypical cores. ORPHA:319160

Congenital myopathy with internal nuclei and atypical cores is a rare genetic skeletal muscle disease characterized by neonatal hypotonia, distal more than proximal muscle weakness, progressive exercise intolerance with prominent myalgias, and mild-tomoderate overall motor impairment with preserved ambulation. Face, extraocular, cardiac, and respiratory muscles are unaffected. Mild cog nitive impairment is also noted in most patients. 